\title{
Mobile Access to Audio and Video Collections in Libraries and Other Cultural Institutions
}

\author{
Carolyn Doi \\ Music Liaison Librarian \\ McGill University \\ Montréal, Québec \\ carolyn.doi@mcgill.ca \\ James Mason \\ Technical Services Librarian \\ Faculty of Music \\ University of Toronto \\ Toronto, Ontario \\ j.mason@utoronto.ca \\ Jared Wiercinski \\ Digital Services and Outreach Librarian \\ Concordia University \\ Montréal, Québec \\ jared.wiercinski@concordia.ca
}

\begin{abstract}
Mobile devices have become commonplace, and are increasingly capable of accessing multi-media resources such as audio and video. Many libraries maintain multi-media digital collections that could be accessed on mobile devices. Mobile devices, however, offer unique display and technical challenges that need to be addressed. The benefits of mobile access to library collections include the promise of increased use and an enhanced user experience. In this article we provide a detailed discussion of the issues related to mobile delivery of digital media, including a literature review, an overview of significant technical issues, and three case studies.
\end{abstract}

\section{Keywords}

mobile computing; streaming media; audio; video; libraries; library collections 


\section{Introduction}

"The mobile revolution can be a critical method in promoting library use and value, dramatically impacting how libraries deliver services to their users" (Murray 245).

The increasing presence of mobile devices is striking, and there is good reason to believe the trend will continue. In 2010 there were over five billion cell phone subscriptions globally (Whitney). Dr. Hamadoun Toure, Secretary-General of the International Telecommunication Union, says, "I am confident that we will continue to see a rapid uptake in mobile cellular services in particular in 2010, with many more people using their phones to access the Internet" (Bailey). The 2009 Horizon Report, published jointly by Educause and The New Media Consortium, says, "for many users, broadband mobile devices like the iPhone have already begun to assume many tasks that were once the exclusive province of portable computers" (Johnston, Levine, and Smith 4). Both the 2009 and 2010 Horizon Report list mobile computing as one of the top trends to watch, defining it as "use of the network-capable devices students are already carrying" (Johnston et al. 5). The Pew Report further illustrates the changing role of mobile devices in our lives, and their ability to provide mobile access to multimedia content. They found that in 2010 , for example, $38 \%$ of cell phone users were accessing the Internet, as compared to $25 \%$ in 2009 (Smith 1).

As we have seen on the web, the streaming of media content boasts seemingly limitless potential. The ability to extend this to mobile devices is also possible (Sauer 21), creating significant opportunities for responsive institutions. Libraries have adapted web technologies to deliver content, and promote online access to their services (Buczynski 2008 262). Furthermore, libraries are beginning to engage their users via mobile phones. Examples include audio tours, text message reference services, text message alerts, and mobile-friendly search engines (Buczynski 2008 262). Museums are responding as well, and have recently started offering audio tours that are accessible by mobile phone (Buczynski 2008 263).

With the addition of full-featured web browsers to mobile devices, there is a real opportunity to provide improved access to media collections (Buczynski 2008 266). These opportunities will just increase with developments in related technologies. The introduction of Apple's iPad into Canada in April 2010, for example, further demonstrates the variety of devices that will be developed as both computer and mobile technology continues to progress. There are a wide variety of possible candidates: libraries' oral history, folklore or special collections; mobile audio course reserves (e.g., Concordia University); mobile film and video collections (e.g., The National Film Board of Canada/NFB); mobile videos of past music concerts or programming events (e.g., the Orange County Library System); mobile access to proprietary music and video databases (e.g., Naxos and Alexander Street Press); mobile access to audiobooks (e.g., OverDrive and NetLibrary); and many other audio or video collections held within libraries. Audio collections have special potential for mobile access, as Buczyski says, because: "Audio, unlike watching video, or reading, can be enjoyed while engaged in a 
wide range of activities" (2006 103). Furthermore, as one small-scale, cross-cultural study found: "The most popular usage context for listening to music on an MP3 player was clearly commuting to school or work" (Nettamo, Nirhamo, Häkkilä 92).

Commercial ventures have been quick to respond, and can be viewed as direct competition to library services. RealNetworks, for example, which specializes in streaming media software, have released an iPhone version of its Rhapsody subscription music service. The iPhone app enables on-demand music streaming to mobile phones (Rosoff). Music sites Spotify, Pandora, Grooveshark, and Last.fm have also launched similar apps.

It is clear, then, that mobile technologies offer libraries the opportunity to provide unprecedented access to their collections.

\section{Literature Review}

A review of the literature revealed good general coverage on the emerging importance of mobile technologies to libraries (e.g., Kroski, Ally and Needham; Griffey; Hahn). Adequate coverage also exists for more specific subjects, such as mobile technology in relation to academic libraries (e.g., Lippincott "A Mobile Future"; Wilson and McCarthy), and for particular services such as reference (e.g., Lippincott "Mobile Reference"), and instruction (e.g., Godwin; Cuddy). Balas' list of web sites and blogs that cover new mobile initiatives is a useful resource for those who want to stay current.

The coverage is uneven, however, on the topic of mobile access to library collections. Only a handful of articles include discussions on the topic, where it is typically addressed within a single section rather than as the focus of the article. Murray provides an excellent overview of mobile library initiatives, with a helpful section on mobile access to library collections (240). She describes mobile access to several parts and formats of a library collection, including access to audio, video, music, ebook, and reference collections, as well as to proprietary databases. Particularly relevant are her descriptions of the AudioReserves2Go service at the Crouch Fine Arts Library at Baylor University, and the OverDrive system. The AudioReserves2Go service provides access to iPods preloaded with the audio files needed for course-related listening, whereas OverDrive enables libraries to provide wired and selective wireless access to ebooks, audiobooks, music, and video, without users having to visit the physical library. Kroski (34) also discusses mobile access to collections, including a brief mention of mobile access to audiobooks via preloaded iPods (at both the Thomas Ford Memorial Library and the St. Joseph County Public Library) and of the New York Public Library's use of the OverDrive system as a part of its eNYP2L service. In his article on using mobile devices for research, Murphy provides a section on mobile access to proprietary databases, though databases that feature audio or video content are never mentioned.

Jeske provides a compelling argument for the importance of audio and video to libraries, reminding us that "some people learn better through viewing and listening, and some people simply don't like to read" (22). She offers several case studies of innovative libraries that incorporate rich media into their services. Of special significance 
is her description of a mobile initiative by the Denver Public Library, where recordings of staff members reading selected children's books from the collection can be accessed through podcasts and on the library's web site.

In a similar vein, Buczynski (2006 98) argues that Ray Bradbury's 1950s Fahrenheit 451 vision of a society where "everyone had audio devices in their ears all the time" has now been realized. Given this reality, he challenges libraries to meet user demand: "While many libraries possess large holdings of music and audio books on CD, consumers today expect online download or live streaming access" (99). His article also includes intelligent discussion of digital rights management (DRM), and of sites and services that provide online access to music and audiobooks. Although he never mentions mobile access explicitly, the implication is clear: "Bridging the audio holdings gap using emerging audio services, consumer audio services, and a risk taking mindset, are the first steps to addressing patron demand for new media content" (103).

Finally, implicit in the idea of libraries providing mobile access to their collections is the belief that mobile learning is a significant form of pedagogy. For a comprehensive and recent (2009) overview of the core issues in mobile learning, see Pachler, Bachmair, and Cook.

\section{Getting Audio and Video Collections onto Mobile Phones}

Recognizing the value of presenting multi-media library collections to mobile devices raises the question of "how" to accomplish this. In this section we discuss some of the basic issues and technologies involved.

Mobile devices range from small "dumb phones", intended mainly for phone calls, to "smart phones" with full-featured browsers capable of accessing the web, emailing, playing audio and video, and more (Noyes). These devices offer libraries an opportunity to reach out to patrons in a new manner. Yet the ability to present media content is under-utilized.

While many libraries are effectively presenting digital collections online mainly for desktop users, mobile users are in fact accessing them. Libraries are not usually tailoring this content to mobile use. Mobile devices have specific issues that need to be addressed, and making an effort to present content appropriately for mobile devices is possible and quite beneficial to a growing percentage of a library's user base. For the purpose of this article we are focusing on "smart phones" or devices capable of a full web experience.

When presenting audio and video collections to mobile devices, libraries must consider whether to stream content or to offer it as a download. Also, the capabilities of various devices need to be kept in mind. Finally, libraries need to consider whether to create content specifically for mobile devices, to adapt or modify existing online material, or to create specific applications for specific devices. 
Both downloading and streaming have strengths and weaknesses. With downloading, a file will be downloaded and stored in the internal memory of the user's device.

Streaming, however, involves content being immediately and continuously delivered to a patron without the media ever residing on their computer or mobile device ("Streaming Audio"). Ohio University Library, for example, is active with podcasting, offering both streaming and downloading options. Patrons have the option of playing the podcast right on the screen as a stream, or downloading the file to play in a media player of their choice (see Figure 1):

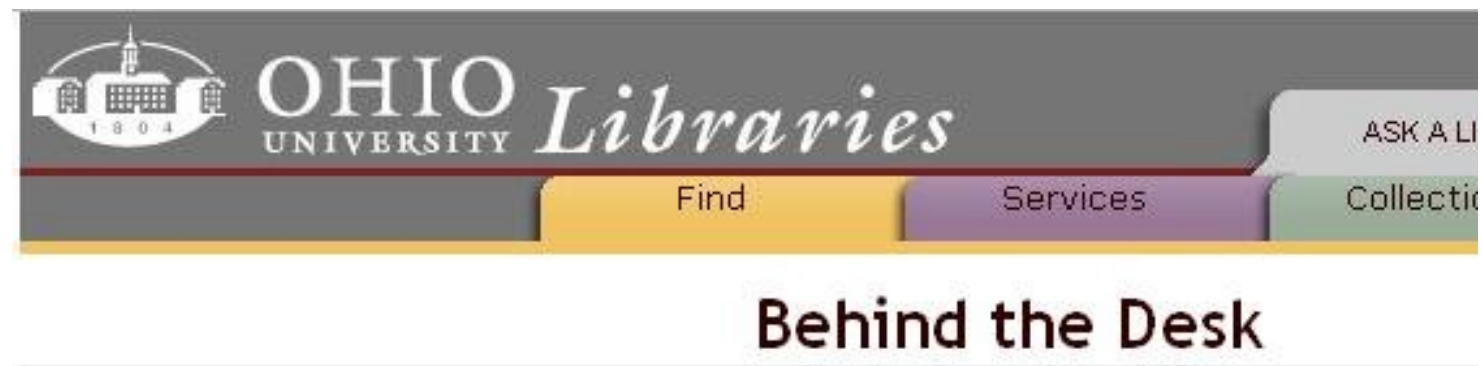

Podcasts from Alden Library

\section{Chinese Language Tour of Alden Library}

September 10th, 2008

Yi Li narrates the updated, interactive audio tour of Alden Library. 28 minutes of audio; the tour should talk you about an hour.

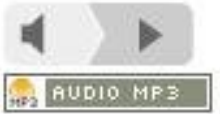

Standard Podcast [27:37m]: Hide Player | Play in Popup | Download

Posted in Audio tours, Podcasts | Comments off

Figure 1: Screenshot of Ohio University Libraries' podcast listing 
Here we see the file streaming through their web site (see Figure 2):

\section{Chinese Language Tour of Alden Library}

September 10 th, 2008

Yi Li narrates the updated, interactive audio tour of Alden Library. 28 minutes of audio; the tour should talk you about an hour.

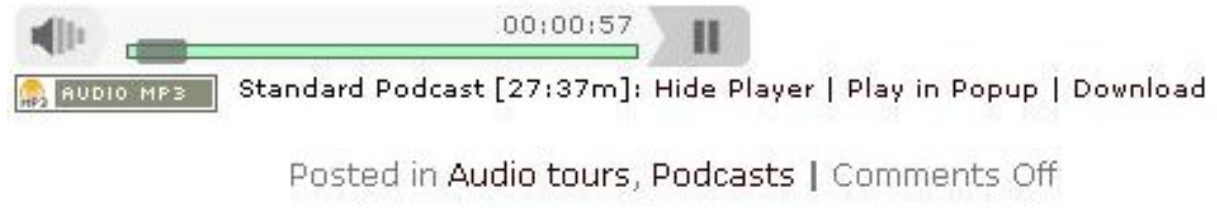

Figure 2: Screenshot of podcast track offered by Ohio University being played

On mobile devices, however, the downloading option does not save the item for use at a later time. Instead, it plays right away in a media player on the user's device. This takes the user away from the context in which the content was presented. This shift may be confusing, and potentially interrupts the user experience. Furthermore, if the file is inappropriate, downloading may be wasteful of time and resources. If we were to view this same page on an iPhone, for example, this is what we would see (see Figure 3):

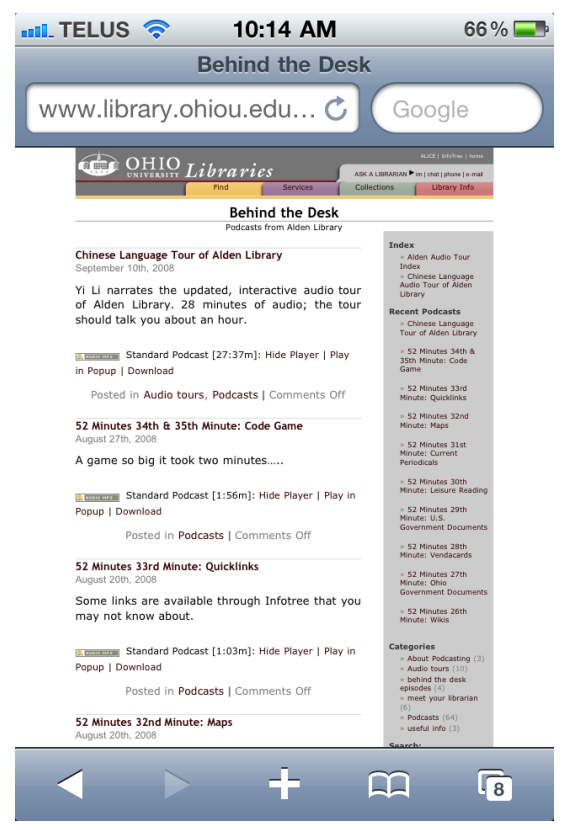

Figure 3: Screenshot of Ohio University Libraries' podcast listing seen on an iPhone screen 
This example is potentially difficult to read and navigate. If you choose to download the file, this is what you would see (see Figure 4):

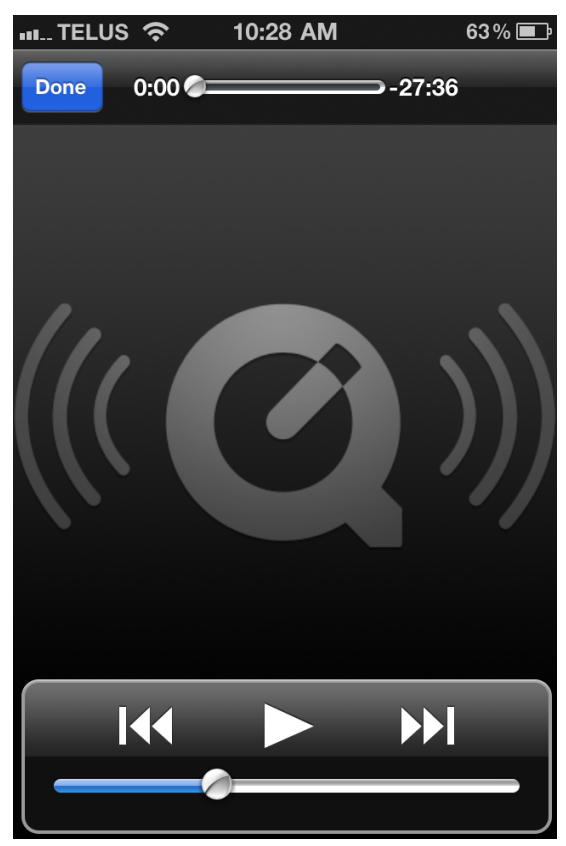

Figure 4: Screenshot of podcast track being played on an iPhone

This takes the user away from the page (s)he was viewing, and the context. Once the video is cleared (closing the page or loading new content), the video will be gone, and the user will need to navigate back to the original web page. As we see in this example, formats are a little less of a variable for downloading than for streaming. 
Dalhousie University offers another example of making podcasts available (see Figure 5).

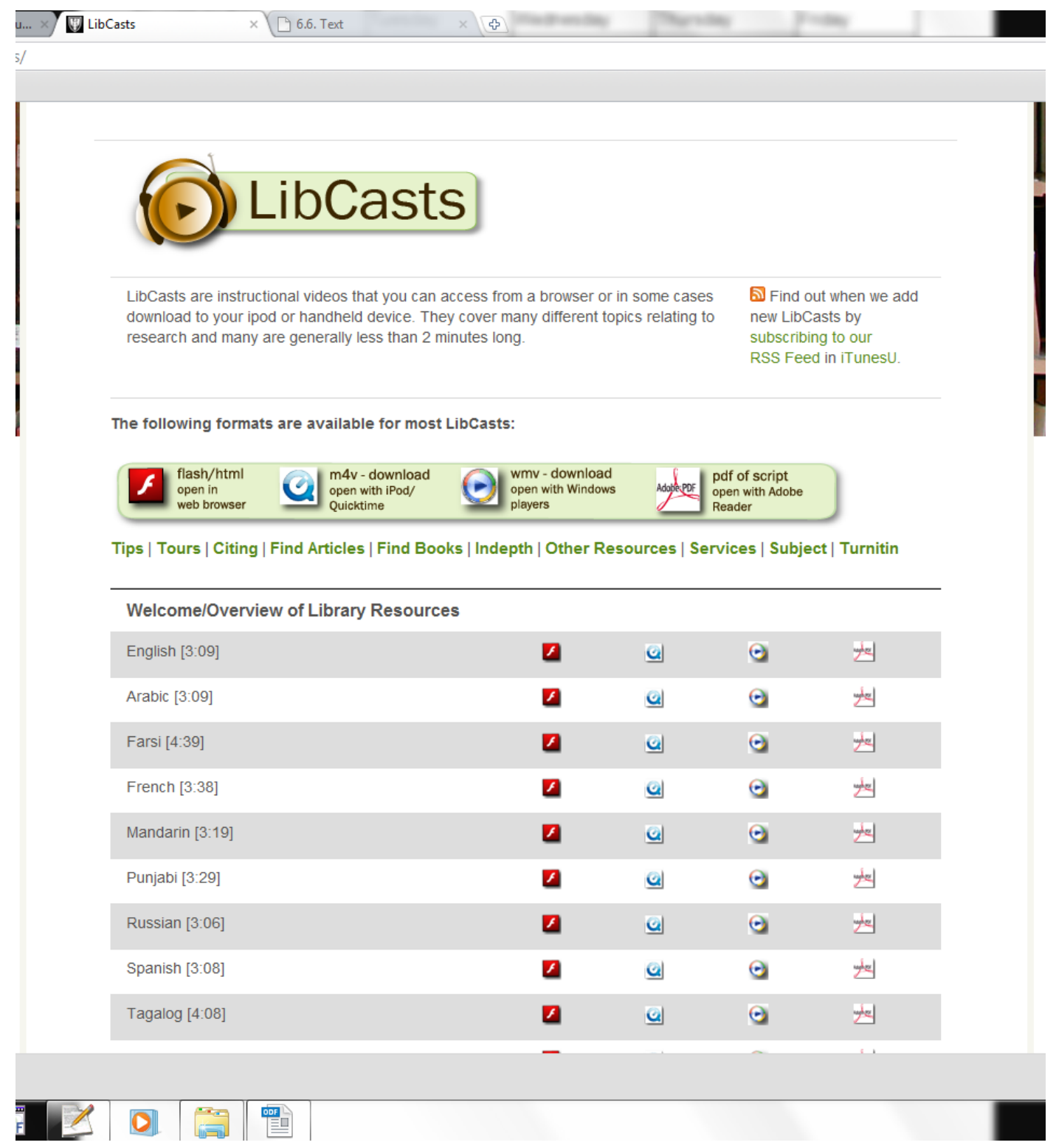

Figure 5: Screenshot of Dalhousie University's podcast listing

Here the options are well laid out in a list. The options are clearly labeled, at the top of the list, as streaming or downloading. The file streams with the Flash version, which opens in a new tab. The other options are downloaded to a computer to access how the user chooses. 
This page renders quite well on smart phones. Here, for example, we can see the page displayed on the iPhone, which renders well on the phone's crisp screen, with fairly readable text (see Figure 6).

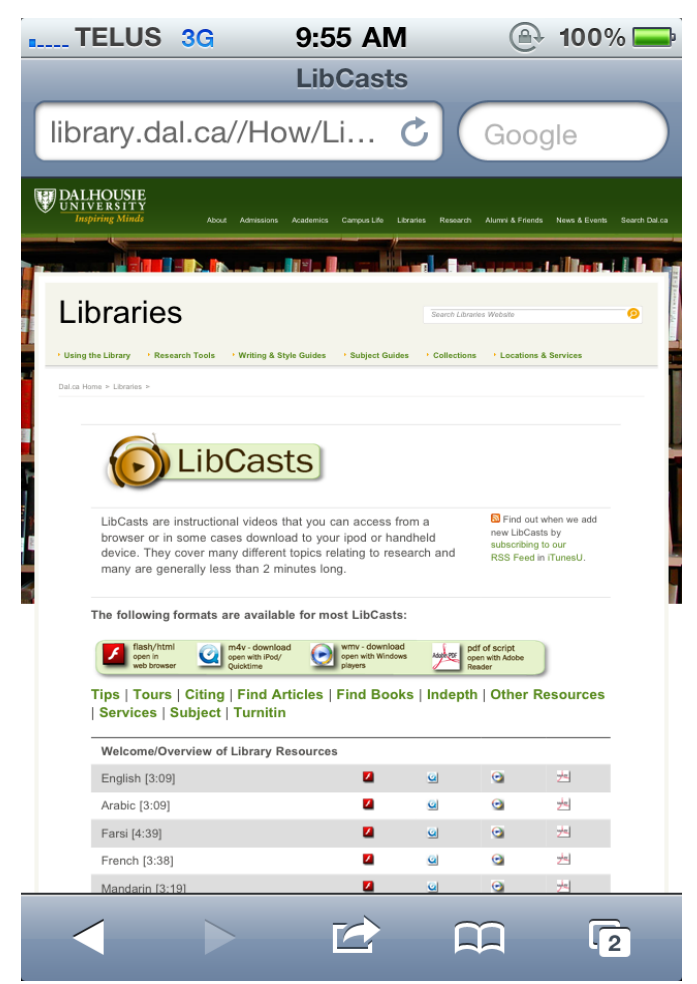

Figure 6: Screenshot of Dalhousie University podcast listing on an iPhone

As with the Ohio University example, however, downloading or streaming a file on a mobile device takes the user away from the context in which the content was originally presented, potentially causing confusion or, even worse, wasting a user's bandwidth in cases when the content was mistakenly selected.

The situation is different on a desktop computer, where streaming technologies are fairly mature, and work well. Flash videos, for example, can be easily embedded in a web site. This is not the case for mobile devices. Support for streaming formats can be spotty and differs widely (Sauer 24). An example illustrating some of the difficulties in providing streaming media can be seen in the following chart published by WFMU Radio (see Table 1): 
Table 1. WFMU Radio Chart illustrating streaming variables

\begin{tabular}{|c|c|c|c|c|c|c|c|}
\hline & iPhone & Blackberry & Android & Windows & Palm OS & Cost & Streams Supported \\
\hline WFMU Radio & $x$ & & & & & $\$ 0$ & MP3 \\
\hline Public Radio Tuner & $x$ & & & & & $\$ 0$ & MP3 \\
\hline Berry Tunes & & $x$ & & & & $\$ 22$ & MP3 \\
\hline Radio Bee & & $x$ & & & & $\$ 0$ & MP3 \\
\hline AOR Radio & & & $x$ & & & $\$ 0$ & MP3 \\
\hline Streamfurious & & & $\bar{x}$ & & & $\$ 0$ & MP3 \\
\hline GSPlayer & & & & $x$ & & $\$ 0$ & MP3/OGG \\
\hline Pocket Tunes Deluxe & & & & & $\mathrm{x}$ & $\$ 20$ & MP3/WMA/OGG \\
\hline Windows Media Player & & & $x$ & & & $\$ 0$ & WMA \\
\hline
\end{tabular}

This chart illustrates some of the software variables, though only a select number of devices were even considered ("WFMU Mobile FAQ"). With streaming, though, context can be preserved and the patron remains right on the web page, allowing for a more structured presentation of material -- how the audio is being received and used.

When creating content for a mobile device, there are a number of issues that make presentation a challenge. Screen size, input options, bandwidth restrictions and device limitations all need to be considered.

Screen sizes are small, and vary from device to device. For audio, associated images such as an album cover and textual information like liner notes are nice features, but will need to be scaled to fit the screen without the need for scrolling, hyperlinking or page turns which can confuse context ("Mobile Web Best Practices" sec. Presentation Issues).

Input must also be considered. Some devices have touch screens, and some don't. The keyboards are almost always small, and thus present typing challenges. URLs and search forms are hard to fill in. Navigation between fields may not occur in the expected order and navigation features such as a "Back Button" may not exist, or a user may not know how to use it ("Mobile Web Best Practices" sec. Input). With video or audio presentation this can be a significant issue. Lengthy search queries invoking artist, title, movement and other metadata fields easily navigated on a desktop can become an obstacle on mobile devices. Providing the most expedient method of accessing content is essential. Radio-like functionality or "play-list" options are ways to limit the need for a user to navigate the resource.

Bandwidth speed and cost are still potential issues for many mobile devices. Latency times can be high, leading to longer loading times for audio tracks. Any associated images will extend loading time. Furthermore, bandwidth can be expensive. Compressed files with images scaled to fit the screen properly can help. Needless to say, content that was not requested, such as advertisements, should be kept to a minimum ("Mobile Web Best Practices" sec. Bandwidth and Cost). 
Device limitations and variations amongst mobile devices offer further challenges. Browser support for features such as scripting (CSS, JavaScript. etc.) can be limited or nonexistent (Buczynski 267; "Mobile Compatibility Tables"). Processing power is limited and varies between mobile devices. Re-flowing pages, laying out tables, and processing unnecessarily long and complex style sheets can all limit functionality and therefore hinder the user experience ("Mobile Web Best Practices" sec. Device Limitations). Not all audio and video file types can play on all devices.

There can be widely disparate characteristics among mobile devices. Input and navigation methods can vary. Different screen sizes may demand different size images, and different capabilities may require different file types. This can make it difficult to provide a consistent user experience across a range of devices. Furthermore, heightened user expectations need to be considered. Mobile users are often goaloriented. If they are attempting to access an audio track, they need to get to it quickly and easily; scrolling, linking and page turning should be kept to a minimum. Effort to preserve the context within which the audio is being presented can enhance a user's experience ("Mobile Web Best Practices" sec. User Goals).

Considering the characteristics and limitations of mobile devices, there are three main ways to deliver content: creating applications, or "Apps", specific for various devices; creating and/or presenting content specifically for mobile consumption, (Wireless Access Protocol or WAP pages for example); or modifying content, (dynamically or statically).

Creating "Apps" is one option. This offers the most control over a user's experience, and the ability to predict what that experience will be. Specific "Apps" will need to be created for all devices the content provider hopes to reach. Programming expertise is also required. Libraries can create the Apps "in house" if they have the qualified staff, or outsource if they have the necessary resources. With Apps, presentation can be tailored to meet the specifications of particular devices. 

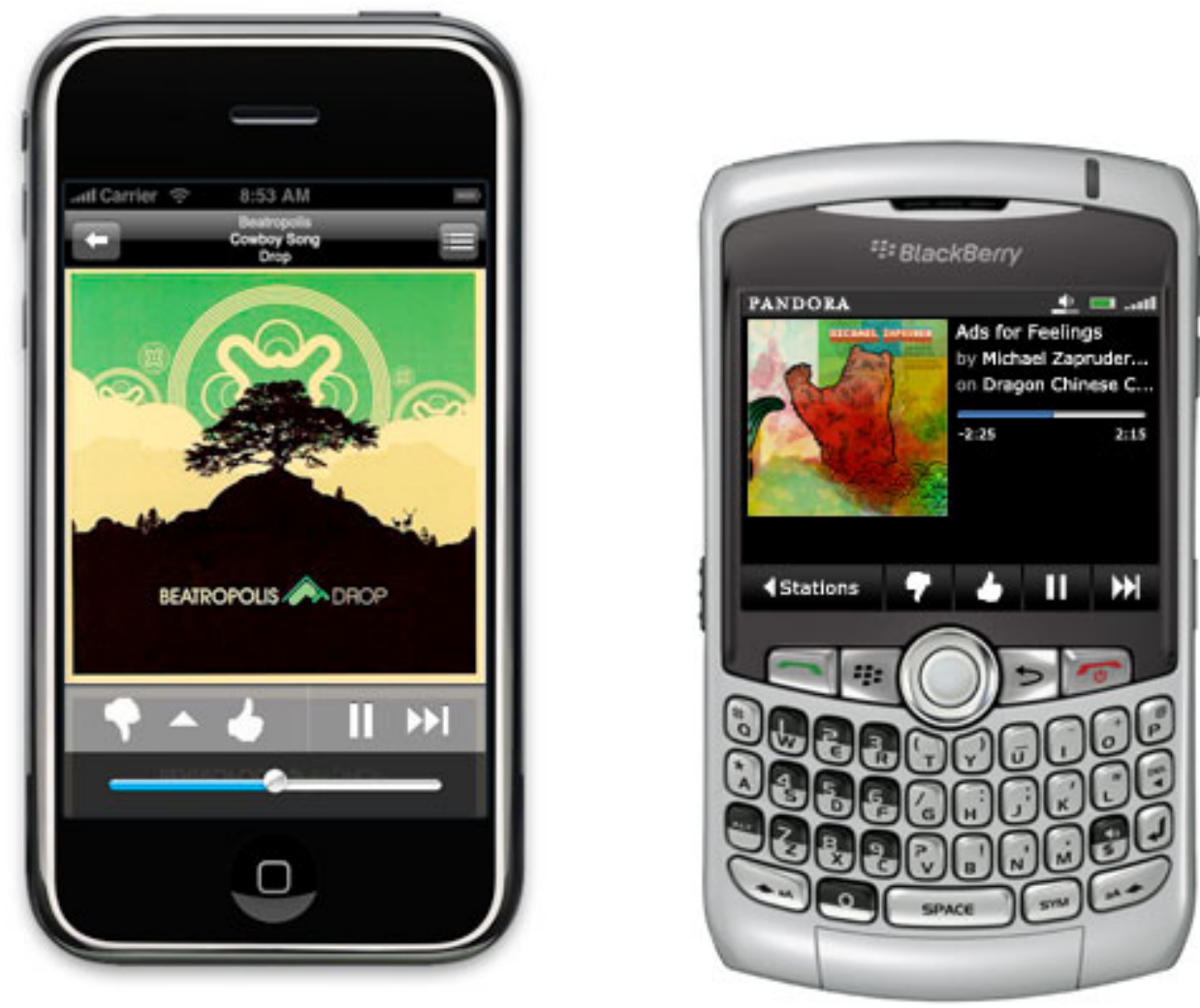

Figure 7: the Pandora App on the iPhone and Blackberry platforms

In Figure 7 we see the App from the popular online audio service Pandora, which is available for both the iPhone and Blackberry platforms. The content is the same but the presentation is specific for the devices. Furthermore, specific capabilities of the device can be exploited.

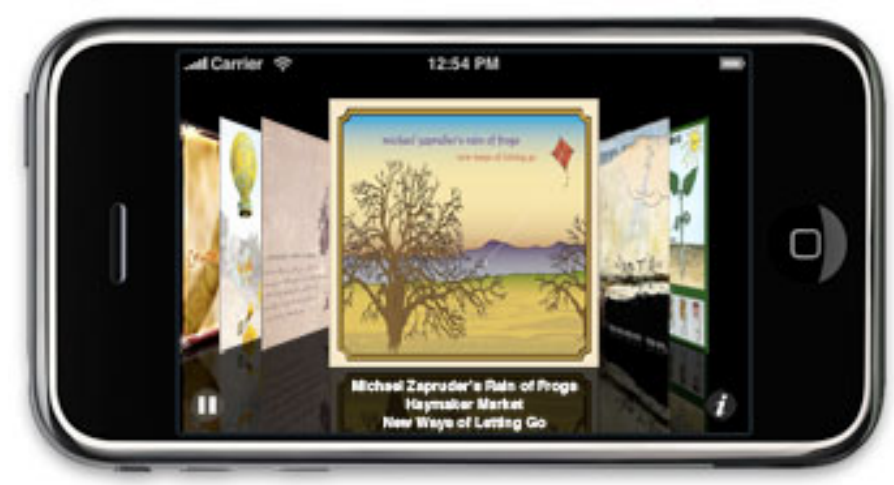

Figure 8: the "cover flow" feature of the iPhone via the Pandora App

In Figure 8 we see Pandora's iPhone App utilising the "cover flow" feature of the iPhone. 
WAP pages are one way to deliver content specifically intended for mobile devices. They require a special mark-up language, WML (Wireless Markup Language), and a specific WAP browser (Jones). This has been a popular choice in the past, although it is not necessarily the best option for presenting media-rich audio or video content.

First, WAP browsers tend to be stripped down. Some support CSS.2, AJAX, and JavaScript, but many do not ("Mobile Compatibility Tables"). Display issues are compounded by variation amongst browsers because some support images and some don't. WAP sites adjust to any mobile device, but often at the expense of many of the advanced capabilities of the web, including, in some cases, streaming media. Many modern phones, however, are quite capable of delivering a full web experience.

Formatting or adapting a standard web page for "smart phones" may be a better option.

Methods for adapting web content include Server-Driven content negotiation, Media Types and Media Queries, or other options such as Common Gateway Interface (CGl) scripting.

With content negotiation, a user's device delivers HTTP headers to a content provider's server. These headers provide valuable information that can help the server determine whether or not a given device is mobile, which MIME types it can handle, (e.g., XHTML MP, WML, HTTP), and sometimes even accepted file types. With this information the server could then redirect the user to corresponding content or style sheets displaying information more appropriately (Jones). With Server-Driven content negotiation, all the action happens in the web server itself, so in some circumstances this can be a great solution for static web pages. It can limit a user's need to type in long URLs, by allowing the server to redirect them from a "home page" to a "mobile home page" where content and file types are presented appropriately (Jones).

Media Types and Media Queries are ways to further refine this process. Media Queries build on the functionality of Media Types. These features can be fully implemented in CSS2, HTML4, or even XML tags. With Media Queries, information from HTTP headers can be combined with links to appropriate CSS style sheets displaying content designed for various different uses. Screen size of users' devices (width and height), screen orientation (portrait or landscape), aspect-ratio(s) and other display type features can all be considered. Media types that can be specified include: 'handheld', 'print', 'projection', 'screen', 'tv', and others ("Media Queries").

CGI Scripting can be another effective way to modify content for mobile devices.

CGI scripting can make a web page more interactive, allowing a web page to respond to an action by the user - executing a search query, for example (Nackerud 223). Libraries can also use CGI scripting to dynamically serve appropriate content to mobile devices. An iPhone could receive content suited for its platform, while a Nokia device receives different content. The diversity in mobile device capabilities is significant. CGI scripting could easily accommodate various devices' specifications such as screen size and browser features, and more advanced specifications such as media file types, which can be difficult to anticipate. 
CGI scripts interact with user information in a couple of ways. This can happen via HTML forms, but could also be through information retrieved dynamically from HTML headers or HTTP User Agent headers, which can recognize the identity of the web browser and, typically, the specific device. Then, with this information, a CGI script could map or mine information about the phone from a data set such as WURFL, and appropriate content or styling of content could then be rendered (Jones). Data sets such as WURFL, referred to as Device Description Repositories, list information such as what that phone/browser is capable of playing/displaying, including formats, screen size and depth, and the navigation keys that are available (Jones). User Agent Profile (UAProf) is another common Device Description Repository.

On a larger scale, institutional delivery of media content requires access to some type of digital library system. For a brief discussion of the main functions and features of these systems see Appendix 1.

Providing media rich content to mobile devices can be an attractive option for libraries as there are many devices capable of delivering an enjoyable user experience. Providing this content to users does, however, require attention to a wide variety of variables.

\section{Mobile access to audio and video collections: three case studies}

In this section, we present three case studies that demonstrate mobile initiatives to enhance access to local audio and video collections. We have selected these projects because they have grown out of grass roots efforts at the institutional level, and may not be well known. They provide a healthy contrast to some of the high-quality mobile initiatives that have recently been launched by proprietary databases of media content, including Naxos (iPhone apps for their Naxos Music Library and Naxos Jazz databases), Alexander Street Press (iPhone and Android support for a number of their databases), OverDrive (mobile support on a variety of devices for audiobooks and music) and NetLibrary (mobile support on a variety of devices for audiobooks). As good as some proprietary databases are, however, they do have their limits, and library users frequently require access to content that these services simply cannot provide.

\section{National Film Board of Canada: "NFB Films" iPhone App}

In October 2009, the National Film Board of Canada (NFB) launched "NFB Films", an iPhone application that offers free viewing of hundreds of NFB films over Wi-Fi or $3 \mathrm{G}$ networks. The motivation for this mobile initiative by the NFB grew out of their mandate to increase access to the film collection for people in remote communities who would not otherwise be able to view these films.

The NFB's history of commitment to increased online access began in earnest in 2000 with the CineRoute pilot project, which was developed in order to make selected films from the NFB collection available by request over the Internet. In the first phase, the 
initial audience for the 800-title collection was students and instructors at colleges and universities, as well as those working at Canadian research centres. Phase two of the project extended the service to elementary and high schools, public libraries and community organizations (Handman 443). In the Estimates report published in 2000, the NFB made a commitment to "continue research and development on the CineRoute project, which will enable the NFB to offer Canada's first cinema-on-demand service via the Internet" (19).

In 2007, the NFB took part in an initiative to explore access to media in the emerging mobile environment. This initiative, called mobiDOCS: Confessions in a Digital Age (http://www.nfb.ca/mobidocs), featured ten 2-minute shorts created for mobile, online, television and cinema, co-produced by Film Australia and the NFB. Content could be viewed on the web or downloaded for use on mobile devices such as the iPod video.

The NFB launched the 'Screening Room' (http://nfb.ca) in January 2009, providing access to hundreds of films from their collection through Flash-based streaming technology. The web service opened up a previously inaccessible collection of Canadiana archives "from historical films dating back to 1928 to current contemporary releases, including award-winning documentaries, animation and fiction" (NFB).

By October 2009 the NFB extended its service to the iPhone and iPod Touch platforms when it released "NFB Films", an iPhone app that offered access to the digitized film collection through mobile Wi-Fi or $3 \mathrm{G}$ networks. One of the highlights was the ability to download content, which could then be viewed in offline contexts -- creating a truly mobile viewing experience. Downloads are only usable for a 48-hour period, after which time they will expire. This is similar to a traditional library circulation model where materials can be borrowed for a predetermined length of time.

Since its release in October 2009, "NFB Films" has been largely successful. By June 1, 2010 the NFB app for the iPhone had been downloaded more than 235,000 times, with 821,000 film views (Lavender). In June 2010 the NFB released "NFB Films for iPad", a free application for the iPad, which offers similar access to the digitized film collection, with added features such as split-screen technology allowing users to browse video and related content simultaneously.

The temporary download access model is successful because it enables institutions to offer access to a large number of materials, negating the need to acquire copyright licenses for individual items. In this case, users have benefited greatly from the digitization of a collection that is difficult to access in person (the physical collection is divided between offices in Montreal and Toronto) but has much to offer in terms of access to Canadian cultural artifacts. Because the video is downloaded before viewing, video quality is high, and plays without the interruptions often experienced while streaming multimedia content. One of the noticeable drawbacks of this case is the heavy reliance on the Apple mobile devices, with no visible moves to expand the service to other smart phones. 


\section{Concordia University Libraries}

Concordia University Libraries developed a project in 2008 to provide access to sound recordings required for course-related listening (Mason and Wiercinski). While course listening requirements are traditionally accessed through physical resources such as compact disc loans, this project explored the idea of making these resources accessible remotely. Initially designed for a web interface, explorations into the adaptation of the project for a mobile interface began in January 2010.

The introduction of web access to audio course reserves was successful, expanding from use in three courses in 2008-09 to nine courses during 2009-10. The majority of students who were surveyed gave positive feedback about the new service.

Furthermore, many indicated that they would be likely to use a mobile-based service for accessing the same audio reserve items instead of, or in addition to, the web based service and compact disc loans. Based on this feedback, a mobile project began in January 2010, exploring two options for mobile access: one was to use existing software to provide access to audio files (ooTunes software), and the other was to make use of emerging web standards to create a mobile-compatible audio player (modified jPlayer).

The first approach used ooTunes, a web and mobile application that allows users to access a central audio library from remote locations. Access is achieved in one of three ways: via a web browser, mobile browser or iPhone app. At Concordia University, the audio files required for course listening were uploaded to a server using the iTunes digital media player application, and student access to the collection was controlled by a shared user name and password. The ooTunes pilot project was successful because students were given multiple options for access to the audio files, through user-friendly interfaces that were designed specifically for mobile access. Access via the iPhone app was particularly well received, since it offered a number of features that enhanced the user experience during playback, including display of album art and music metadata (such as artist, album and track title information), and the ability to simultaneously browse for and listen to content. While feedback on the iPhone app was largely positive, there was some concern about its five-dollar fee, which the library reimbursed during the pilot project.

The second approach was to build a customized streaming audio player based on emerging standards that emphasize accessibility across web and mobile platforms. The project was based on jPlayer, a free, open source audio player that relies on the HTML5 standard to provide streaming access to audio files hosted by the institution. While the original jPlayer template was designed for use in a web context, its integration with HTML5 and JavaScript instead of Flash made it possible to use for audio playback in a mobile context. The project utilized mobile-specific HTML code such as the <viewport> meta tag, which customizes display for mobile browser dimensions (see Appendix 2 for the HTML code used in this project) and a customizable CSS style sheet that allows for interface optimization for mobile viewing (see Appendix 3 to see the entire CSS style sheet). The mobile prototype (accessible at: http://www.sqacbm.org/carolyn/) is an 
interesting example of the potential of the newly developed HTML5 standard and its flexibility for use in both web and mobile environments.

Both approaches allowed the institution to provide temporary, streaming access to audio content, thereby adhering to copyright legislation. Although many institutions can now provide mobile access to content by way of commercial subscription-based audio databases, this project gave the library more control over which parts of its collection to make available, as well as the ability to host content that was simply not available through its subscription databases. Furthermore, the Concordia example is promising because it offers an alternative approach to providing access to sound recordings for course-related listening. This approach looks beyond both the traditional model of lending physical materials for fixed periods of time, and the "desktop" model of online access which requires being tethered to a stationary computer.

\section{Denver Public Library: "Stories for Kids" Podcasting Program}

The Denver Public Library's (DPL) program provides access to children's stories through podcasts that can be downloaded to a computer or mobile device.

The project is an initiative to offer story time for kids in new contexts outside the library building. The DPL has explored this idea before with the "Phone-a-Story" program, which allows kids to call the library and access a collection of audio stories for different age groups, in either Spanish or English. The "Stories for Kids" podcasts project (http://podcast.denverlibrary.org) expands access to children's stories to both the web and mobile platforms.

The podcasts are accessible in two ways: through RSS feed subscription or through download on the library web site. The RSS feed has been featured on the iTunes store and various online podcasting directories (e.g., podcastdirectory.com). The Denver Public Library podcast page is easy to navigate in a mobile browser, though it has not been optimized for mobile viewing.

When the project started in 2006, it only featured stories in the public domain in an effort to adhere to copyright legislation that specified: "reading, recording, and distributing the audio of a copyrighted story requires permission from the publisher and author, unless the clip is less than three minutes in length" (Jeske 3). Soon after, the DPL took steps to offer access to stories outside the public domain by obtaining permissions from publishers individually. This effort was somewhat successful: several publishers responded, and permissions were obtained to offer access to titles as long as attribution was specified with each podcast. The collection has grown to more than seventy stories which are available for free download and private use.

This case is interesting because podcasts tend to be used to distribute content generated by the institution, such as library audio tours or lectures, where copyright is straightforward. It also addresses the issue of converting existing content and taking advantage of new technology to make the collection more widely accessible. Mobile 
accessibility could be improved in this case by optimizing the podcasts page for viewing on mobile browsers.

\section{Conclusion}

The literature on mobile access to library audio and video collections has, up until now, focused on what we would call semi-mobile access (i.e. mobile access that requires a trip to the physical library, as is the case with preloaded iPods) or on proprietary, multimedia databases such as OverDrive. The sole exception to this trend is Jeske's discussion of the Denver Public Library's podcasting service. We have attempted to narrow this gap by discussing truly mobile, institutionally-generated initiatives such as those of the National Film Board of Canada and Concordia University. We have also provided expanded analysis of the Denver Public Library project.

Libraries will need to continue to innovate in order to meet and exceed user expectations. As Jeske puts it: "While libraries have been very good at looking to one another for best practices, the most innovative online resources and services are being developed and delivered outside the library world" (22). Sites like YouTube, SoundCloud, GrooveShark, Last.fm and Citysounds.fm are good examples of such innovation. Their creative mobile applications continue to raise the standards with userfriendly interfaces and ingenious features. The mobile revolution provides significant opportunities for libraries, with their media-rich collections and unique content, to take inspiration from these projects and develop forward-looking services. 


\section{Works Cited}

Ally, Mohamed, and Gill Needham. M-libraries 2: A Virtual Library in Everyone's Pocket. London: Facet, 2010. Print.

Bailey, Diane. "United Nations Radio: More Mobile Phone Users in 2010." United Nations Multimedia, Radio, Photo and Television. United Nations, 15 Feb. 2010. Web. 27 Aug. 2010. $<$ http://www.unmultimedia.org/radio/english/detail/90889.html>.

Balas, Janet L. "Taking the Library to the User." Computers in Libraries 30.4 (2010): 33. Library, Information Science \& Technology Abstracts. EBSCO. Web. 5 Aug. 2010.

Bradbury, Ray. Fahrenheit 451. New York: Simon and Schuster, 1967. Print.

Buczynski, James A. "Libraries Begin to Engage Their Menacing Mobile Phone Hordes Without Shhhhh!" Internet Reference Services Quarterly 13.2 (2008): 261-269. . ProQuest. Web. 22 Aug. 2010.

$<$ http://www.informaworld.com/10.1080/10875300802103916>.

---. "The Library Patron Prefers Listening: Living in Ray Bradbury's Personal Audio Universe." Internet Reference Services Quarterly 11.2 (2006): 97-103. Web. 20 Aug. 2010. <http://www.informaworld.com/10.1300/J136v11n02 07>.

Cuddy, Colleen. "Mobile Video for Education and Instruction." Journal of Electronic Resources in Medical Libraries 7.1 (2010): 85-89. Library, Information Science \& Technology Abstracts. EBSCO. Web. 29 Aug. 2010.

Griffey, Jason. Mobile Technology and Libraries. New York: Neal-Schuman Publishers, 2010. Print.

Godwin, Peter. "Information literacy gets mobile in Vancouver." Journal of Information Literacy 3.2 (2009): 91-95. Library, Information Science \& Technology Abstracts. EBSCO. Web. 29 Aug. 2010.

Hahn, Jim. "Mobile learning for the twenty-first century librarian." Reference Services Review 36.3 (2008): 272-288. Library, Information Science \& Technology Abstracts. EBSCO. Web. 29 Aug. 2010.

Handman, Gary. Video Collection Development in Multi-Type Libraries: A Handbook. The Greenwood library management collection. Westport, Conn: Greenwood Press, 2002. Print. 
"Introduction to Composite Capabilities / Preferences Profile (CC/PP)." The Web Standards Project. (2004): n. pag. Web. 25 Aug. 2010. $<$ http://www.webstandards.org/learn/articles/askw3c/feb2004/>.

Jeske, Michelle. "Tapping Into Media." Library Journal 133.15 (2008): 22-25. Business Source Complete. EBSCO. Web. 25 Aug. 2010.

Johnson, L., Levine, A., and R. Smith. The 2009 Horizon Report. Austin, Texas: The New Media Consortium, 2009. Web. 22 Aug. 2010. $<$ http://www.nmc.org/pdf/2009-Horizon-Report.pdf>.

Johnson, L., et al. The 2010 Horizon Report. Austin, Texas: The New Media Consortium, 2010. Web. 30 Aug. 2010. $<$ http://net.educause.edu/ir/library/pdf/CSD5810.pdf $>$.

Jones, Robert. "Creating Web Content for Mobile Phone Browsers, Part 2." O'Reilly Media - Technology Books, Tech Conferences, IT Courses, News. 20 Feb. 2004. n. pag. Web. 25 Aug. 2010. <http://www.oreillynet.com/wireless/2004/02/06/mobile browsing.html>

Kroski, Ellyssa. "On the Move with the Mobile Web: Libraries and Mobile Technologies." Library Technology Reports 44.5 (2008): 1-48. ProQuest. Web. 22 Aug. 2010.

Lavender, Terry. "NFB Films for iPad and Canada Day." The Vancouver Observer, 2010. Web. 29 Aug. 2010.

Lippincott, Joan K. "A Mobile Future for Academic Libraries." Reference Services Review 38.2 (2010): 205-13. Web. 22 Aug. 2010. $<$ http://dx.doi.org/10.1108/00907321011044981>

---. "Mobile Reference: What Are the Questions?." Reference Librarian 51.1 (2010): 111. Library, Information Science \& Technology Abstracts. EBSCO. Web. 29 Aug. 2010.

Mason, James, and Jared Wiercinski. "Streaming Audio Services in Canadian Academic Libraries." Music Reference Services Quarterly 12.3/4 (2009): 69-91. Library, Information Science \& Technology Abstracts. EBSCO. Web. 31 Aug. 2010.

McElhearn, Kirk. "Send audio and video to your iPad." Macworld_27.8 (2020): 60. Web. 25 Aug. 2010.

"Media Queries." Ed. Håkon Wium Lie et al. World Wide Web Consortium (W3C). W3C Candidate Recommendation. July, 27. 2010. N. pag. Web. 25 Aug. 2010. http://www.w3.org/TR/css3-mediaqueries/ 
Mobile Compatibility Tables." QuirksMode - for All Your Browser Quirks.

Recommendation 29 (2008): n. pag. Web. 25 Aug. 2010.

<http://www.quirksmode.org/m/table.html>.

"Mobile Web Best Practices 1.0 : Basic Guidelines." Ed. Charles McCathieNevile and Jo Rabin. World Wide Web Consortium, (W3C). July, 2008. N. pag. Web. 25 Aug. 2010.

Murphy, Joe. "Using Mobile Devices FOR Research." Online 34.3 (2010): 14-18. Library, Information Science \& Technology Abstracts. EBSCO. Web. 29 Aug. 2010.

Murray, Lilia. "Libraries 'like to move it, move it'." Reference Services Review 38.2 (2010): 233-249. Library, Information Science \& Technology Abstracts. EBSCO. Web. 5 Aug. 2010.

Nackerud, Shane A. "The potential of CGI: using pre-built CGI scripts to make interactive Web pages." Information Technology and Libraries 17.4 (Dec. 1998): 222-9. Library Lit \& Inf Full Text. WilsonWeb. Web. 30 Aug. 2010.

Nettamo, Esa, Mikko Nirhamo, and Häkkilä Jonna. "A Cross-Cultural Study of Mobile Music: Retrieval, Management and Consumption." Proceedings of the 18th Australia Conference on Computer-Human Interaction: Design: Activities, Artifacts and Environments. Sydney, Australia. New York, NY, USA: ACM , 2006. 87-94. Web. 20 Aug. 2010. <http://doi.acm.org/10.1145/1228175.1228193>

National Film Board. 2000-2001 Estimates. Part III -- Report on Plans and Priorities. The Minister of Public Works and Government Services, 2000. Web. 29 Aug. 2010.

---. National Film Board's New Online Screening Room Provides Instant Access to 700+ Productions. NFB, 2009. Web. 29 Aug. 2010.

---. "The NFP iPhone App is now available." News. National Film Board of Canada, 2009. Web. 29 Aug. 2010.

Noyes, Katherine. "Technology News: News: Smartphones vs. Dumb Phones: No Contest." Welcome to TechNewsWorld. Web. 27 Aug. 2010. <http://www.technewsworld.com/story/55446.html?wlc=1282913790>.

Pachler, Norbert, Ben Bachmair, and John Cook. Mobile Learning: Structures, Agency, Practices. New York: Springer, 2009. Print.

Rosoff, Matt. "Rhapsody Approved for IPhone" Cnet News. CBS Interactive, 10 Sept. 2009. Web. 31 Aug. 2010. <http://news.cnet.com/8301-13526 3-1034966627.html> 
Sauer, Jeff. "Mobile media: the future is now." EContent 25.6 (2002):20-25. Expanded Academic ASAP. Web. 25 Aug. 2010.

Smith, Aaron. "Mobile Access 2010 | Pew Internet \& American Life Project." Pew Research Center's Internet \& American Life Project. Pew Research Center, 7 July 2010. Web. 30 Aug. 2010. $<$ http://www.pewinternet.org/Reports/2010/Mobile-Access-2010/ Summary-ofFindings.aspx>.

"Streaming audio." PC Magazine. Ziff Davis, n.d. Web. 25 Aug. 2010. $<$ http://www.pcmag.com/encyclopedia term/0,2542,t=streaming audio\& $\mathrm{i}=52132,00 \cdot \mathrm{asp}>$.

"WFMU Mobile FAQ." WFMU-FM 91.1 (Jersey City, NJ; 90.1/Hudson Valley, NY), n.d. Web. 25 Aug. 2010. <http://wfmu.org/mobile faq.html>.

Whitney, Lance. "Cell Phone Subscriptions to Hit 5 Billion Globally." Cnet Reviews. CBS Interactive, 16 Feb. 2010. Web. 27 Aug. 2010. <http://reviews.cnet.com/8301-13970 7-10454065-78.html>.

Wilson, Sally, and Graham McCarthy. "The Mobile University: from the Library to the Campus." Reference Services Review 38.2 (2010): 214-232. Library, Information Science \& Technology Abstracts. EBSCO. Web. 22 Aug. 2010. 


\section{Appendix 1: Key Features and Functions of Digital Media Libraries}

Anyone looking to purchase or develop software in order to set up a mobile-friendly digital media library for their institution will want to be aware of some of the more important features that are commonly found in these systems. Keeping a checklist of desired features and functionality will help in evaluating different commercial options, and also with making the choice of whether or not to buy or build; but perhaps most importantly, it will help to ensure that your digital media library ends up doing everything you want it to, both from an end-user and an administrative perspective. In this section we will describe some key features to be aware of. Before getting to that, however, it will be helpful to review briefly the component parts of a digital media library system.

Digital media library systems, generally speaking, require software to address five basic functions: editing (i.e. rearranging, remixing, or changing the media files), encoding (i.e. converting raw media files into a format that can be streamed), streaming (i.e. software that sends media files from where they are stored to a user's computer or mobile device), organizing or managing (i.e. some type of content or digital asset management system), and distributing (i.e. a front-end web site or portal where users access the media content). The first four (i.e. editing, encoding, streaming, and organizing or managing) are "back-end" functions, which are typically not directly accessible to the end-user. The fifth (i.e. distributing), is a "front-end" function, meaning the visible, tangible part where end-users engage with content. These five functions can be addressed by using a single, unified software system, or more commonly by combining a variety of separate software pieces together. The system may be hosted locally on the institution's own servers or externally, by using a commercial hosting service. Key "back-end" features to be aware of are listed in Table 1; key "front-end" features" are listed in Table 2.

Table 1: Key "back-end" features of digital media library systems

\begin{tabular}{|l|l|}
\hline Feature & Description \\
\hline Batch importing and encoding & $\begin{array}{l}\text { Batch importing and encoding allows you } \\
\text { to add multiple files at a time, which is } \\
\text { important for an efficient work-flow. }\end{array}$ \\
\hline Encoding for mobile devices & $\begin{array}{l}\text { Make sure that the system can encode } \\
\text { media files into the format(s) supported by } \\
\text { the mobile devices that you are targeting. }\end{array}$ \\
\hline Administrator-created playlists & $\begin{array}{l}\text { It is often necessary to group media files } \\
\text { together (e.g, the different movements of } \\
\text { a musical work), so that playback is } \\
\text { continuous and in a set order. }\end{array}$ \\
\hline Automated metadata indexing & $\begin{array}{l}\text { Any system that can extract metadata } \\
\text { from imported media files (e.g., artist, } \\
\text { album and track titles from MP3 audio } \\
\text { files) will save time. }\end{array}$ \\
\hline Authentication & Make sure that the software supports your \\
\hline
\end{tabular}




\begin{tabular}{|l|l|}
\hline & $\begin{array}{l}\text { institution's authentication system (e.g., } \\
\text { Active Directory/LDAP). }\end{array}$ \\
\hline Web-based audio and video editor & $\begin{array}{l}\text { The ability to edit media files can be } \\
\text { important (e.g., adding subtitles to a video; } \\
\text { cropping or rearranging content). }\end{array}$ \\
\hline
\end{tabular}

Table 2: Key "front-end" features of digital media library systems

\begin{tabular}{|l|l|}
\hline Feature & Description \\
\hline Accessible on mobile devices & $\begin{array}{l}\text { Make sure that your digital library is } \\
\text { accessible on the mobile devices that you } \\
\text { are targeting. }\end{array}$ \\
\hline User-created playlists & $\begin{array}{l}\text { Users appreciate the ability to create, } \\
\text { save, and share playlists. }\end{array}$ \\
\hline Web 2.0 functionality & $\begin{array}{l}\text { Providing support for Web 2.0 functionality } \\
\text { such as commenting, rating, user } \\
\text { generated content, and RSS makes for an } \\
\text { engaging and interactive site. }\end{array}$ \\
\hline $\begin{array}{l}\text { Permanent links, embed codes, and } \\
\text { sharing }\end{array}$ & $\begin{array}{l}\text { Providing support for permanent links, } \\
\text { embed codes, QR codes, and sharing } \\
\text { (e.g., automated posting on popular social } \\
\text { networking sites) will help to ensure that } \\
\text { your content is accessible from a variety } \\
\text { of entry points. }\end{array}$ \\
\hline
\end{tabular}




\section{Appendix 2: HTML code for Concordia's mobile-friendly jPlayer}

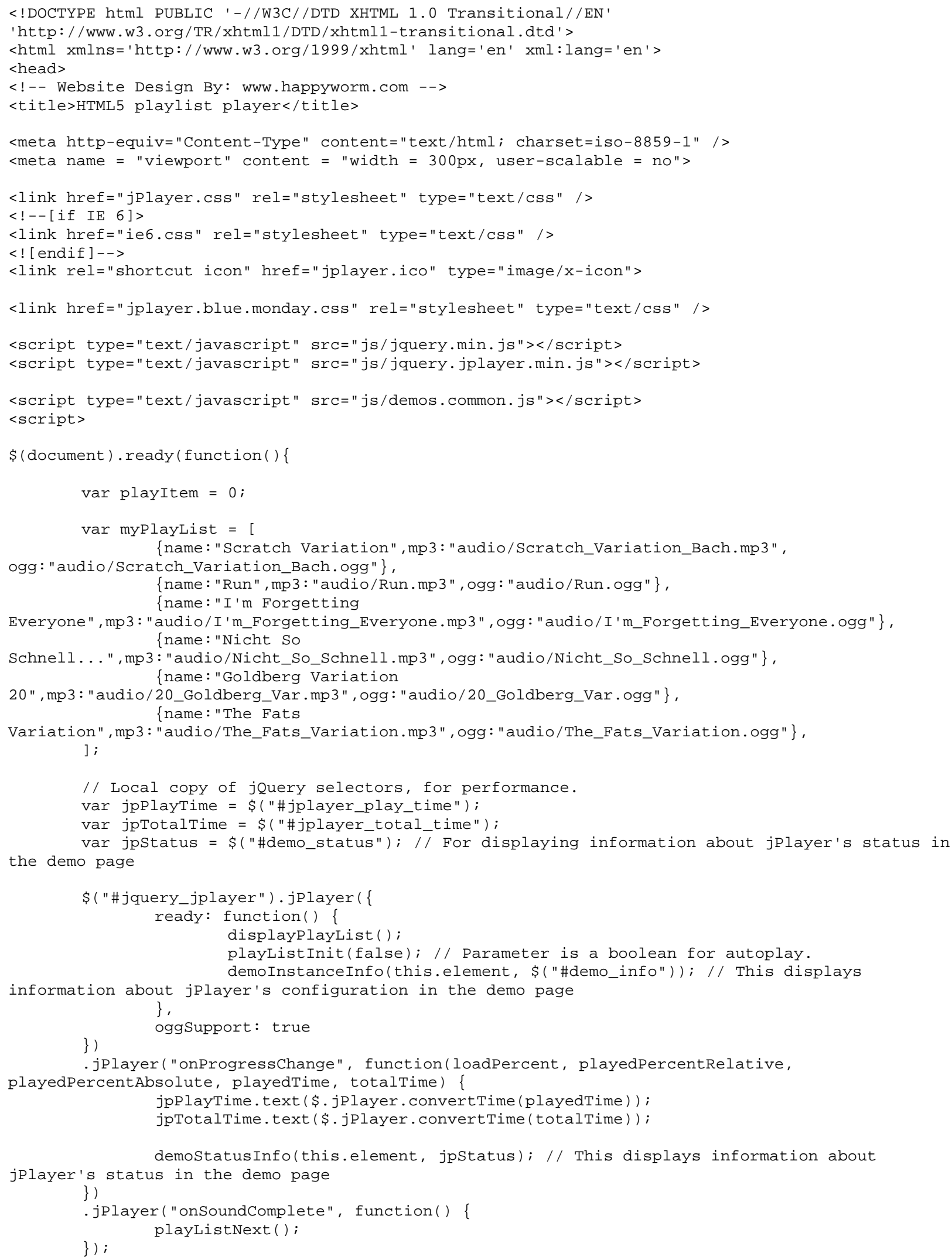


Partnership: the Canadian Journal of Library and Information Practice and Research, vol. 6, no. 1 (2011)

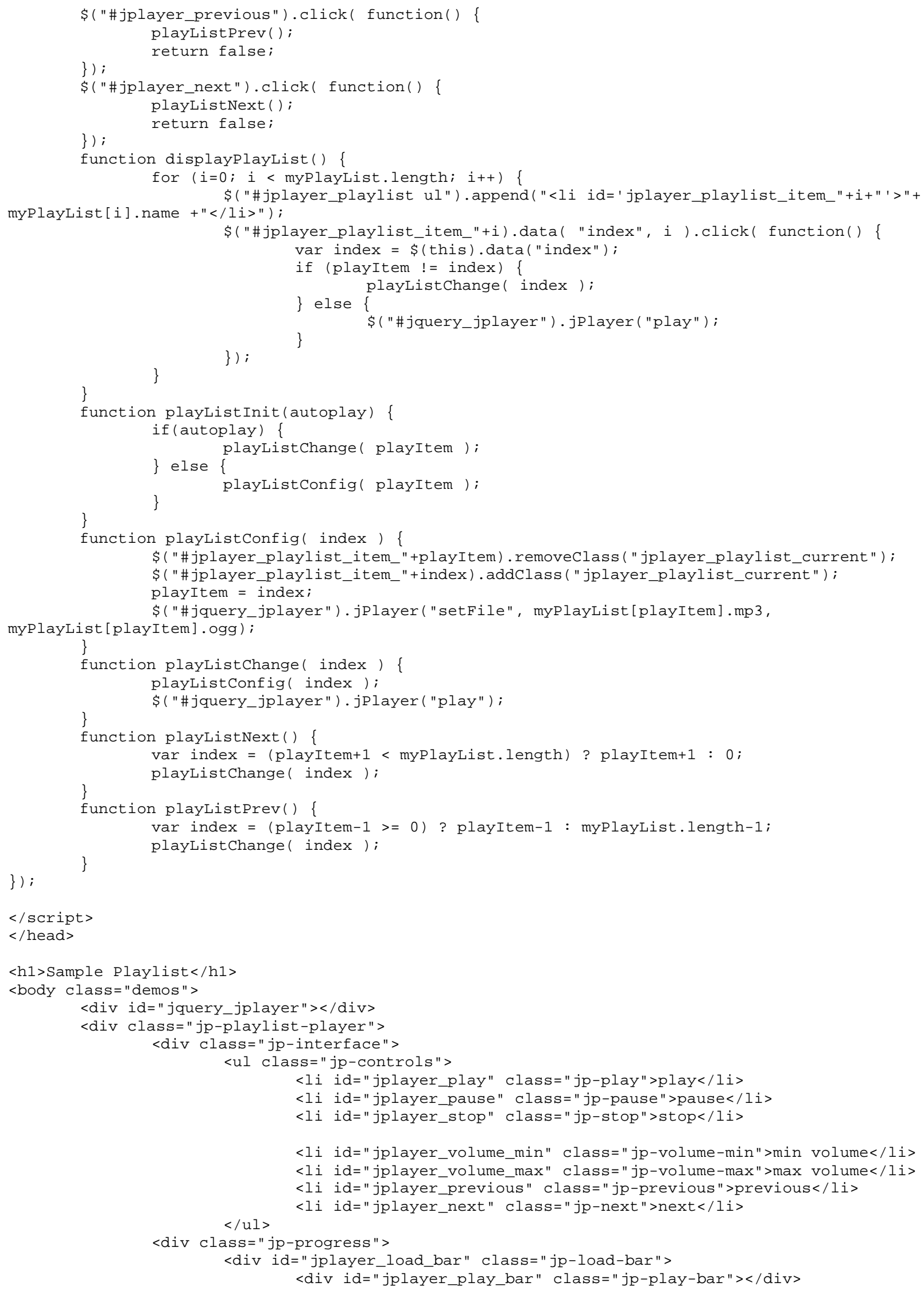


Partnership: the Canadian Journal of Library and Information Practice and Research, vol. 6, no. 1 (2011)

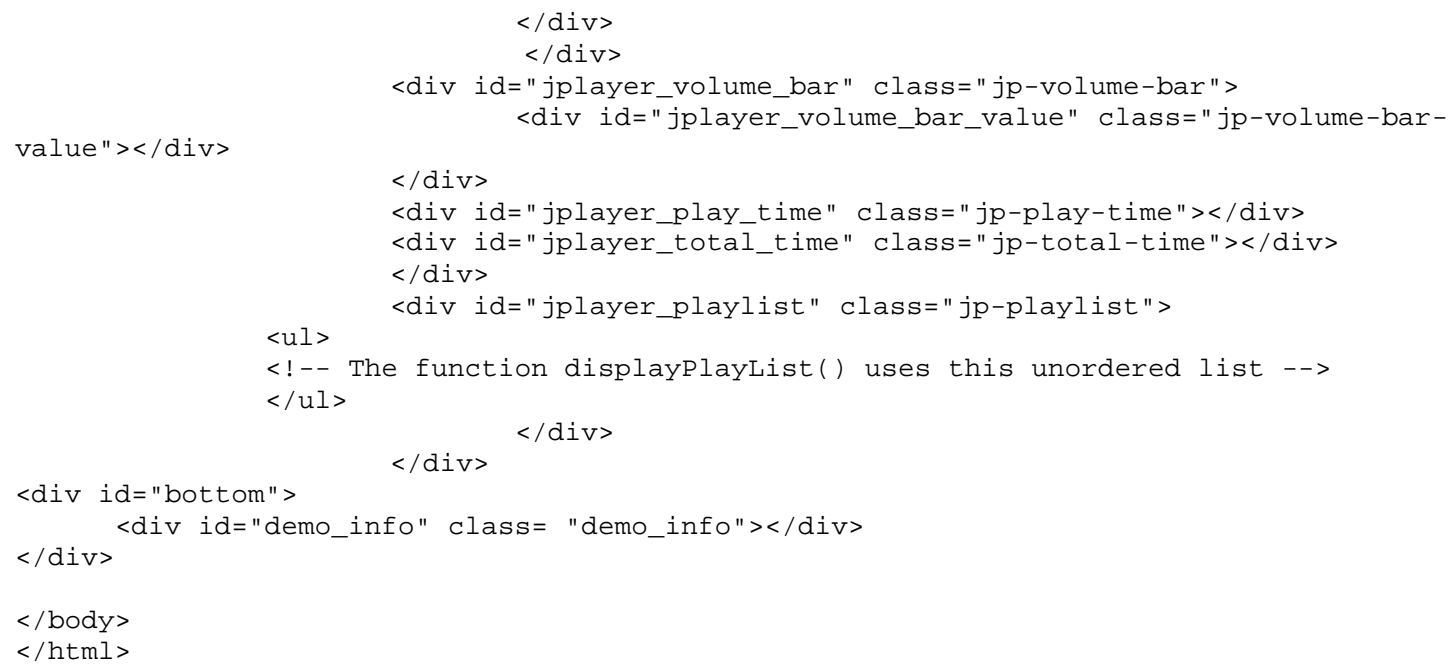




\section{Appendix 3: CSS Style Sheet for Concordia's mobile-friendly jPlayer}

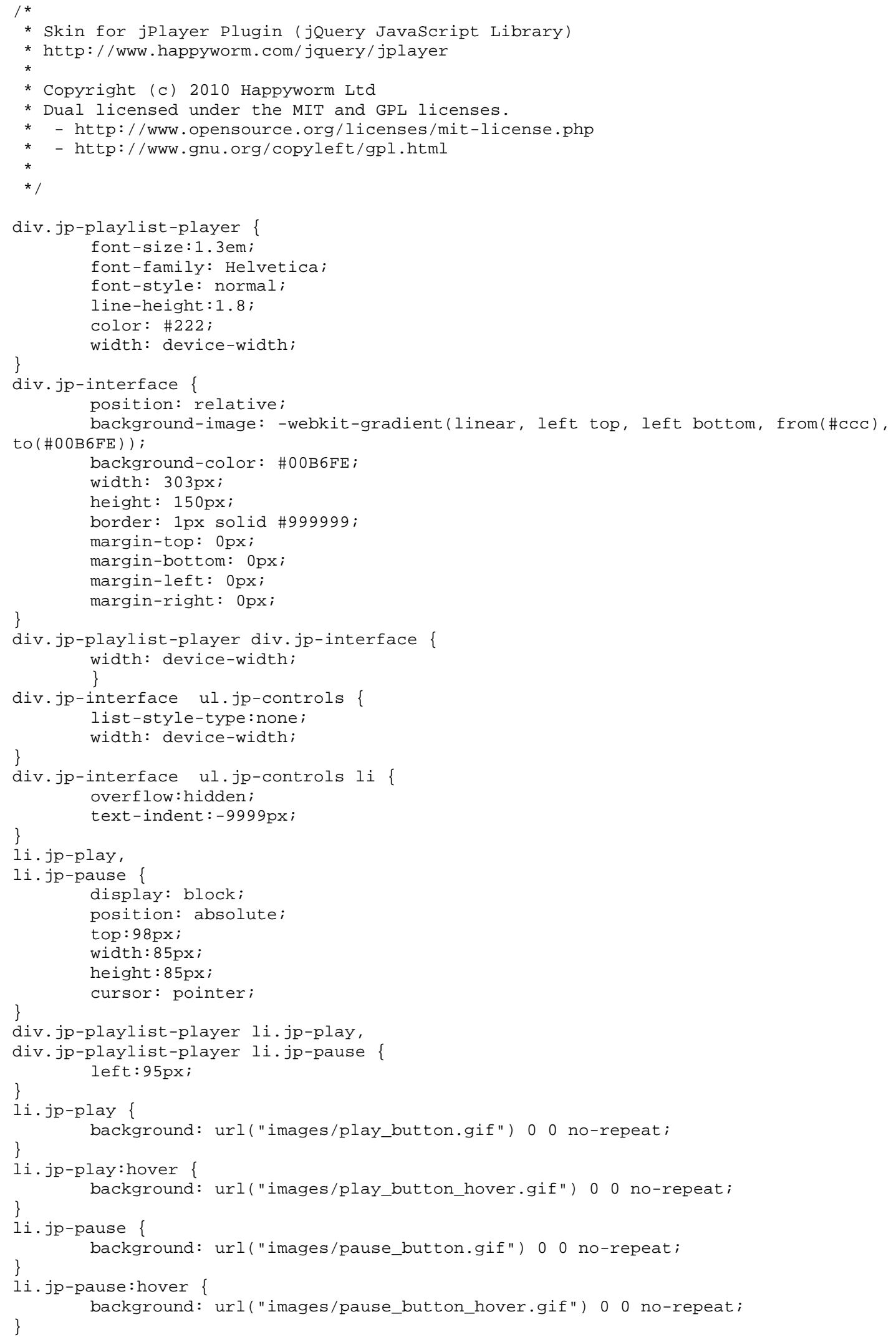




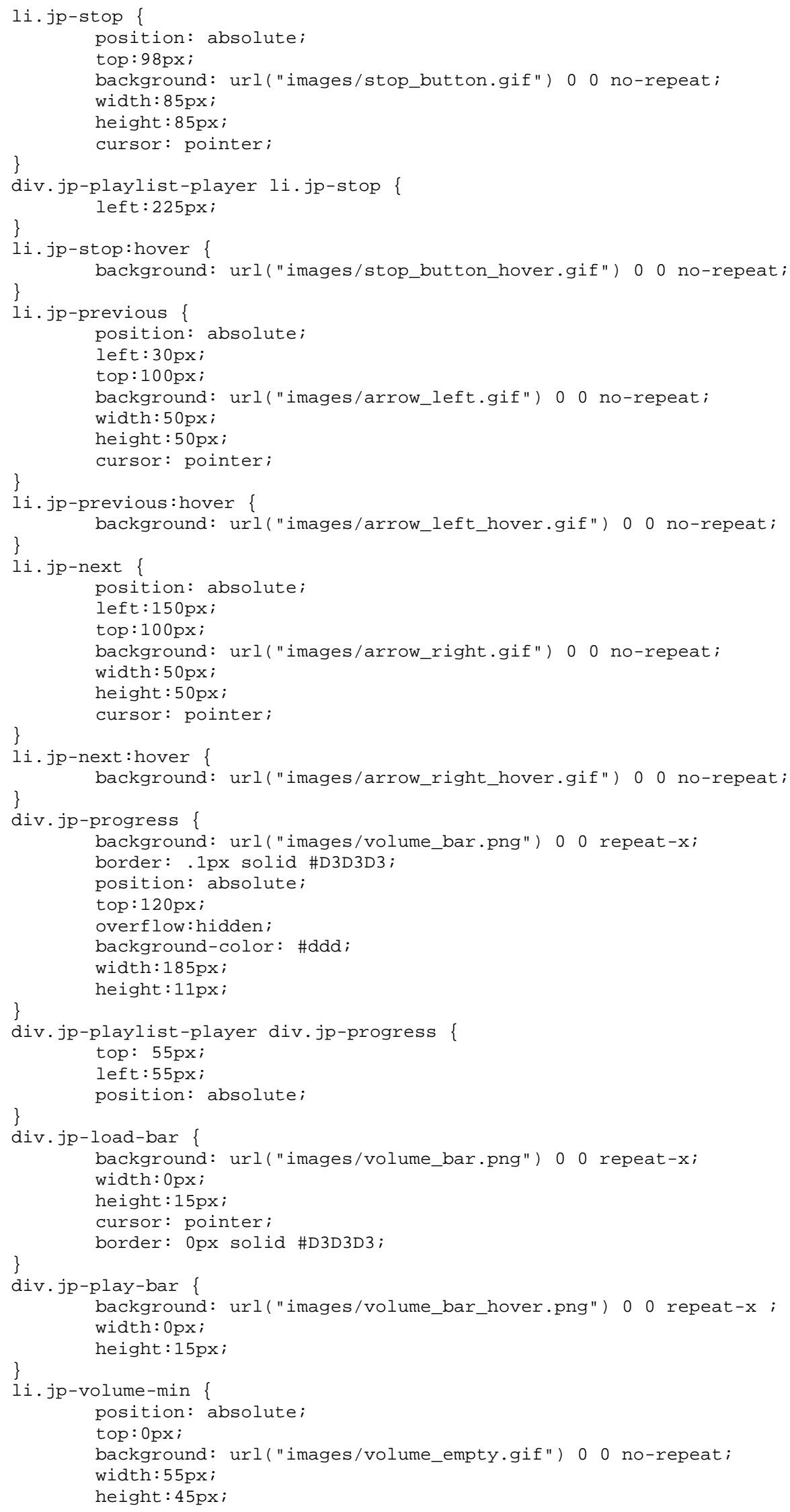




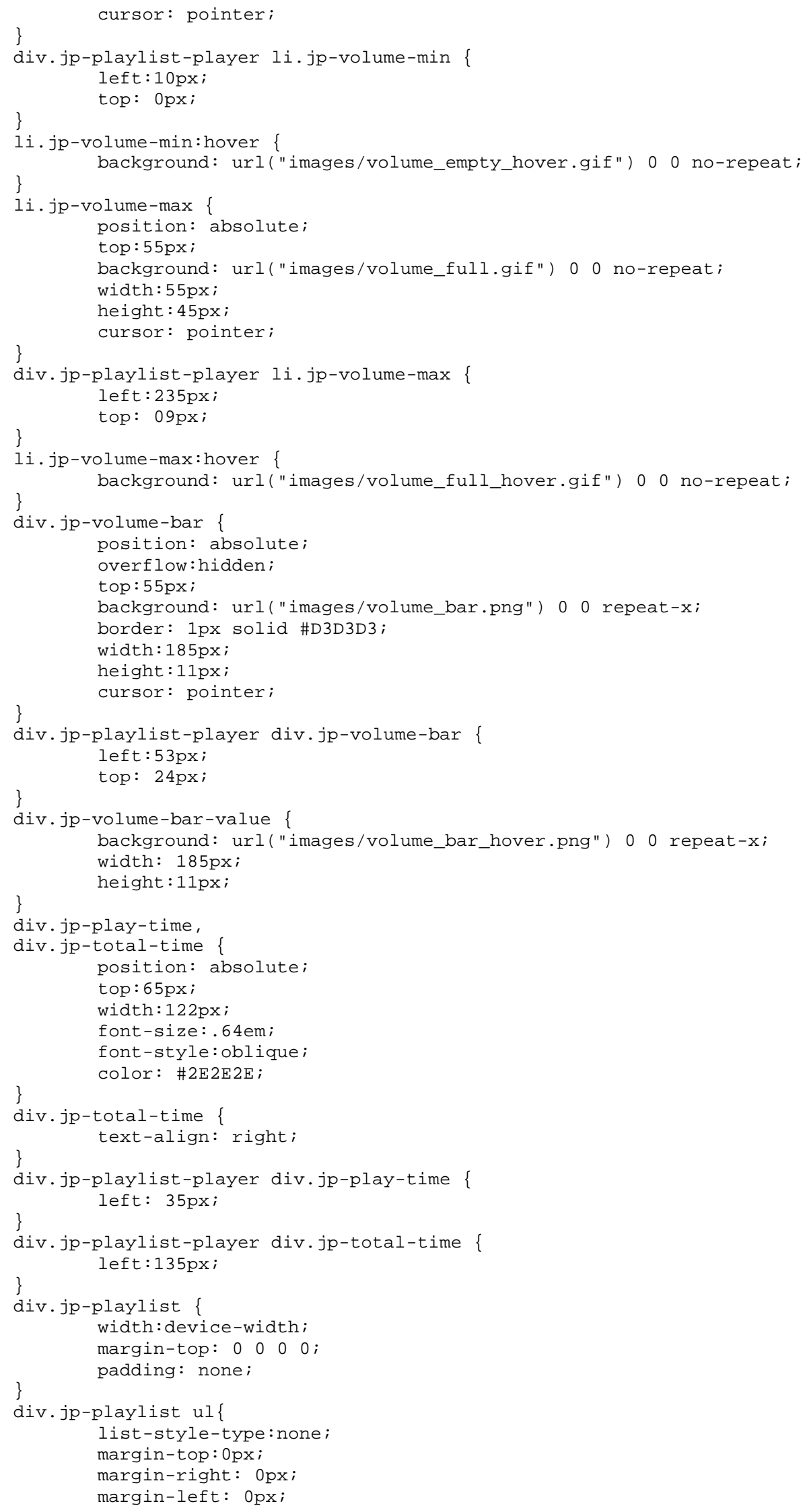




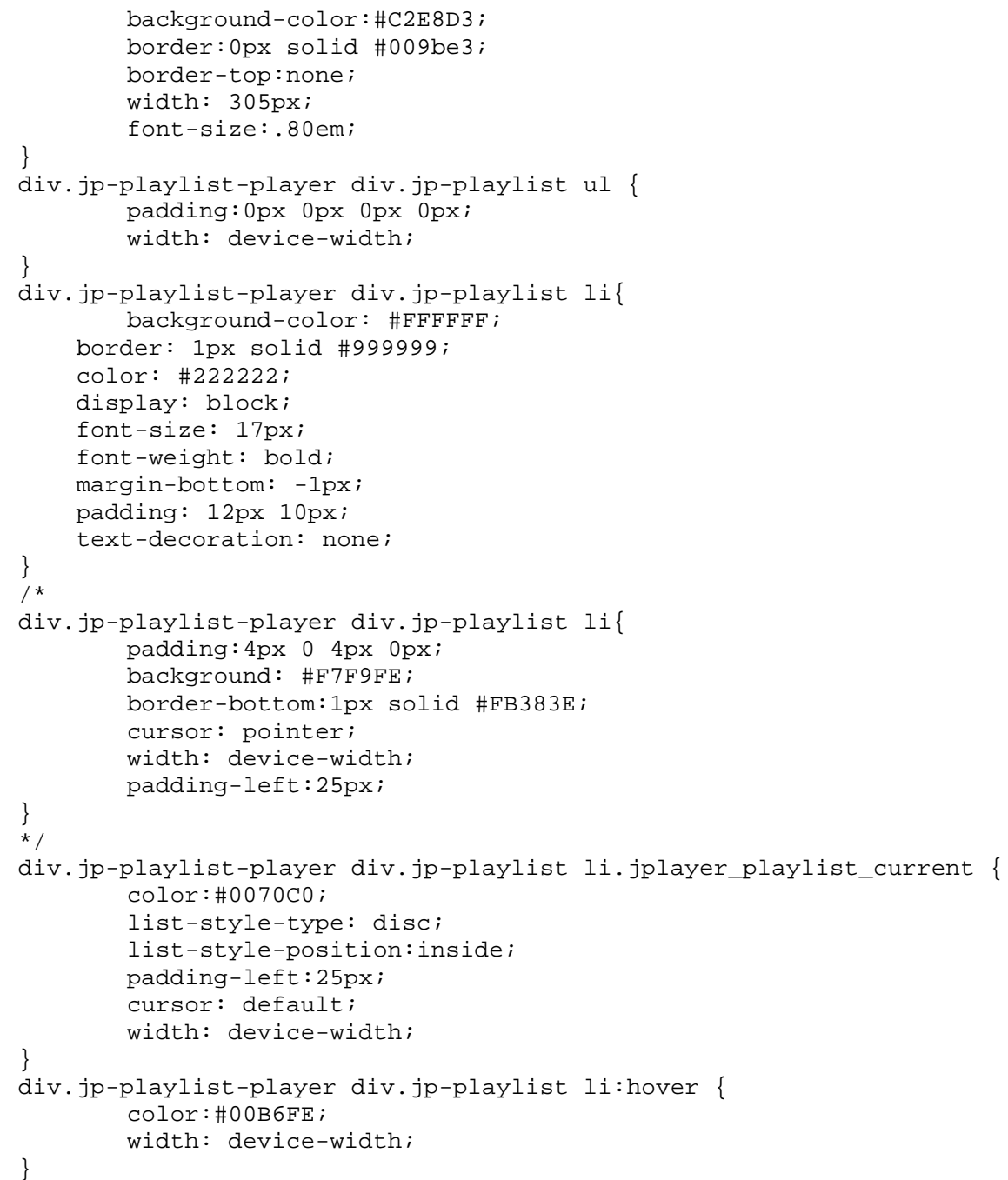

